\section{A deliberação e seus}

momentos nas

conversações em

sociedades divididas

Deliberation across Deeply

Divided Societies: Transformative Moments

Resenha do livro "Deliberation across

Deeply Divided Societies:

Transformative Moments" de Jürg

Steiner, Maria Clara Jaramillo, Rousiley

C. M. Maia e Simona Mameli

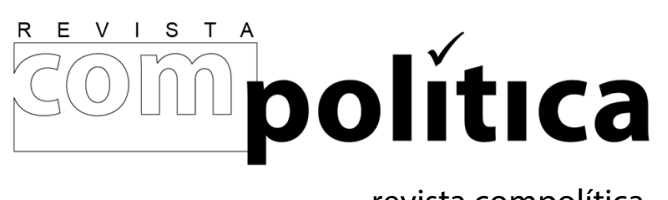

revista compolítica 2019, vol. 9(1)

compolitica.org/revista

ISSN: 2236-4781

DOI: 10.21878/compolitica.2019.9.1.288

O Open Access Journal

\section{Gabriella Hauber}

Universidade Federal de Minas Gerais

[Minas Gerais Federal University]

\section{Pedro Henrique Bicalho Camelo}

Universidade Federal de Minas Gerais

[Minas Gerais Federal University]
Fernanda Nalon Sanglard

Universidade Federal de Minas Gerais

[Minas Gerais Federal University] 


\title{
A deliberação e seus momentos nas conversações em sociedades divididas
}

\author{
Gabriella HAUBER \\ Fernanda Nalon SANGLARD \\ Pedro Henrique Bicalho CAMELO
}

"virada deliberativa" na Teoria Democrática (Dryzek, 2000) ganhou força nos
anos 1990, sobretudo a partir dos estudos de teóricos como Jürgen Habermas,
como uma das alternativas ao modelo agregativo, no qual a decisão é tomada por meio do voto da maioria. Na democracia deliberativa, as decisões e possíveis soluções para os conflitos seriam definidas por meio de trocas de razões mutuamente aceitáveis e que levariam a um entendimento final. Nesse contexto, há procedimentos ideais para que a deliberação ocorra da maneira mais justa possível, como racionalidade argumentativa, inclusão, igualdade moral e política entre os participantes e não coerção (Habermas, 2011). Tais procedimentos foram alvo de várias críticas, muitas vezes pautadas na ideia de que se tratavam de princípios inalcançáveis na prática, ou que poderia ser mais excludentes do que inclusivos (Miguel, 2014; Mouffe, 2005; Sanders, 1997; Young, 1999).

A partir das críticas, sobretudo aquelas direcionadas à racionalidade, a teoria deliberativa passou por uma série de desdobramentos, e outras formas de comunicação, para além da troca de razões, foram discutidas como parte dos processos deliberativos, como retórica, humor e histórias de vida. Abarcar esses outros aspectos pode, por exemplo, favorecer a inclusividade e o entendimento mútuo. Contudo, será possível que ocorra esse entendimento em contextos marcados por conflitos profundos? A deliberação nesses casos é algo viável? Tendo como foco as discussões de cidadãos ordinários em sociedades extremamente divididas, o livro "Deliberation across Deeply Divided Societies: Transformative Moments" (Steiner et al., 2017) investiga o que chamam de diferentes momentos deliberativos e busca responder essas questões.

Escrita pelo pesquisador Jürg Steiner, em parceria com Maria Clara Jaramillo, Rousiley Maia e Simona Mameli, a obra defende a relevância da deliberação para a prática política, considerando que a sociedade precisa de mais deliberação. Todavia, os autores reforçam 
que defender tal aspecto não os leva a considerar que o sistema político deva se basear apenas em deliberação.

Ao tentar responder às críticas que consideram o modelo deliberacionista utópico, os autores partem do pressuposto de que a deliberação é um continuum que vai de momentos não deliberativos a momentos de deliberação completa. "Nesse continuum, estabelecemos um ponto de corte entre altos e baixos níveis de deliberação, com o último não incluindo deliberação alguma" (p.3, tradução nossa ${ }^{1}$ ). Ou seja, os procedimentos ideais da deliberação não estão presentes a todo momento, pelo contrário, há momentos de maior justificação de posicionamentos, de maior respeito e outros sem nenhum dos critérios deliberativos, por exemplo (Steiner et al., 2017).

É desafiador analisar a deliberação em contextos de conflito extremo, nos quais o diálogo poderia nem mesmo acontecer. Mas são esses mesmos contextos que mais necessitam de processos deliberativos, para que seja possível um entendimento mútuo e que as situações de conflito sejam amenizadas. Steiner et al. (2017) analisam grupos focais de três contextos distintos, todos tendo em comum situações de violência extrema: a) ex-guerrilheiros e exparamilitares na Colômbia; b) sérvios e bósnios na Bósnia; c) policiais e moradores de favelas no Brasil.

Tendo em vista que muito já se discutiu sobre resolução de conflitos em sociedades divididas, Steiner et al. (2017) fazem uma breve revisão desses estudos, que apontaram, por exemplo, a importância do diálogo, da tentativa de entender o outro, da inclusão e da mediação para amenizar conflitos (Drake and McCulloch, 2011; Maddison, 2015). Contudo, ainda há uma lacuna de trabalhos empíricos sobre a dinâmica de discussões entre cidadãos sobre a construção de uma cultura de paz nas sociedades onde vivem - lacuna essa que o livro busca preencher.

Apesar de reconhecerem a importância da elite política e dos espaços de poder para a resolução de conflitos, alinhados ao defendido por Dryzek (2005), o livro foca em como cidadãos ordinários discutem soluções para se alcançar a paz em situações de conflito

\footnotetext{
${ }^{1}$ No original: On this continuum, we establish a cutoff point between high and low levels of deliberation, with the latter including no deliberation at all".
} 
profundo. Por que focar em discussões entre cidadãos e não entre líderes políticos? Os autores explicam que os líderes "tendem a basear seu poder em suas respectivas identidades de grupo. Portanto, eles têm interesse em manter as divisões profundas" (Steiner et al., 2017, p.19, tradução nossa ${ }^{2}$ ). Para analisar os diferentes momentos deliberativos dessas discussões, Steiner e suas parcerias desenvolveram a metodologia dos Momentos Transformativos da Deliberação - Deliberative Transformative Moments (DTM), que será explicada na próxima seção.

Esta resenha é inspirada na própria organização do livro e está organizada da seguinte maneira: primeiramente, vamos explicar a metodologia adotada pelos pesquisadores, assim como a organização dos grupos focais. Em seguida, entraremos nas análises, discutindo como diferentes elementos e atores contribuem para o alto nível da deliberação ou para diminuir a qualidade deliberativa (momentos deliberativos). Por fim, concluiremos apresentando as principais contribuições do livro, críticas que podem ser vislumbradas e implicações para futuros estudos.

\section{Momentos transformativos}

Uma das propostas do livro é apresentar o conceito de Momentos Transformativos da Deliberação (DTM) e a metodologia utilizada para analisar os atos de fala em grupos de discussão distintintos. É justamente este o modelo teórico-metodológico usado pelos autores em suas pesquisas no Brasil, na Colômbia e na Bósnia e Herzegovina.

O conceito de DTM é utilizado por eles para compreender os momentos "altos e baixos" dos grupos de discussão realizados nesses países. Por entenderem a comunicação como um continuum, eles reforçam que a deliberação ocorre em momentos específicos das discussões e estão interessados em compreender quais momentos são esses e o que faz com que haja um alto nível de deliberação.

A ideia dos momentos transformativos - ou seja, circunstâncias que levam a manter, baixar ou aumentar o nível de deliberação - foi desenvolvida ampliando as perspectivas

\footnotetext{
${ }^{2}$ No original: "tend to base their power on their respective group identities. Therefore, they have a vested interest in maintaining the deep divisions".
} 
anteriormente adotadas por outros autores, como as reflexões sobre o "transformative incident", de Lyn Carson, e sobre os "turning points", de Simon Niemeyer.

Steiner, Jaramillo, Maia e Mameli esclarecem no livro que um alto nível de deliberação permite que a discussão flua de modo respeitoso, já quando os participantes não se escutam ou agem de modo desrespeitoso, haveria um baixo nível de deliberação. Partindo dessa premissa e da proposta de compreender os atos discursivos individuais (individual speech act), o método utilizado parte de quatro categorias de codificação do DTM: 1) o ato discursivo mantém o nível alto da deliberação; 2) transforma o nível da discussão de alto para baixo; 3) mantém o baixo nível de deliberação; 4) transforma o nível da discussão de baixo para alto.

Conforme Steiner et al. (2017), os atos de fala são sempre analisados em contexto, nunca isoladamente. Desse modo, os autores se preocuparam em acompanhar detalhadamente o curso da discussão e das narrativas, para identificar o contexto em que as intervenções de cada participação eram feitas. Ou seja, mais do que considerar uma fala específica, consideraram as manifestações anteriores e seguintes, para analisar os atos de fala em relação.

Uma vantagem na utilização do modelo se faz por permitir capturar o fluxo da discussão, e não apenas falas isoladas. Todavia, faltou à obra esclarecer quanto tempo em geral duram esses momentos e por quanto tempo os atos de fala permanecem em cada categoria nos grupos de discussão pesquisados. Um outro aspecto que pode suscitar críticas é o fato de a identificação dos DTMs depender de questões subjetivas, que poderiam variar conforme o entendimento do analista sobre os procedimentos.

Nesse sentido, os próprios autores observam que o Índice de Qualidade do Discurso Discourse Quality Index (DQI), proposto por Steiner para compreender o provimento de razões (que vai da não justificação à justificação sofisticada), teria a vantagem de ser mais preciso nesse aspecto. Entretanto, carrega a desvantagem de analisar os proferimentos isolados, sem considerar os fluxos dos atos de fala. Bächtiger e Parkinson (2019) argumentam que o DQI também não é sensível ao contexto ou ao objetivo conforme se esperava, por não levar em conta funções diferentes desempenhadas pelos atores no 
processo de discussão nem ser voltado a uma comunicação que não visa proporcionar bons argumentos.

Apesar das críticas aos dois modelos, DTM e DQI, eles representam uma tentativa importante de criar modelos de análise para a compreensão dos momentos deliberativos e dos tipos de argumentação que em geral são usados em grupos de discussão. Nesse aspecto, a obra tem a grande vantagem de apresentar, especialmente o DTM, de modo claro e transparente, visto que os dados coletados nos três países foram disponibilizados pelos pesquisadores no site http://www.ipw.unibe.ch/research/deliberation/index_eng.html, por meio dos áudios e das transcrições dos grupos de discussão em língua original e traduzidas para o inglês.

\section{Outras formas de deliberar: emoções, histórias de vida, humor e mudez}

Steiner et al. (2017) realizam a análise dos Momentos de Transformação Deliberativa (Transformative Deliberative Moments) a partir de quatro aspectos: histórias de vida, racionalidade, humor e mudez. Habermas foi bastante criticado por uma suposta supervalorização da racionalidade em detrimento a outras formas de comunicação, como as analisadas pelo livro. As críticas ressaltam, sobretudo, que a valorização da racionalidade afasta a teoria de um dos seus princípios, a inclusividade (Miguel, 2014; Mouffe, 2005; Sanders, 1997; Young, 1999). Para os críticos, exigir uma comunicação estritamente racional reserva a deliberação para os poucos que conseguem articular suas falas em uma argumentação bem fundamentada. Os próprios autores do livro retomam e endossam essas críticas, afirmando que Habermas, ao focar na racionalidade e na justificação, acaba por excluir as narrativas e imagens dos processos deliberativos . Alinhados a essas críticas, Steiner et al. (2017) mostram, por meio de casos empíricos que outras formas de comunicação, como histórias de vida e humor, podem ser positivas para a deliberação.

Contudo, antes de abordarmos especificamente os achados dos autores, é preciso fazer uma ressalva às críticas direcionadas à teoria habermasiana. No nosso entendimento, de fato, Habermas dá ênfase à racionalidade comunicativa em sua teoria, mas isso não quer dizer 
que ele é contra ou exclui outros tipos de comunicação na deliberação. O filósofo alemão já discutiu, por exemplo, a dimensão afetiva e a reflexividade com foco na empatia, que seria "um pré-requisito emocional para assumir a perspectiva do outro, que requer que todos assumam o ponto de vista de todos os outros" (Habermas, 1990, p. 112, tradução nossa). Uma série de fatores pode contribuir para a empatia entre os participantes de uma deliberação, dentre eles, as histórias de vida (Polletta e Lee, 2006; Steiner, 2012).

As críticas a essa suposta supervalorização da racionalidade na teoria deliberativa habermasiana, em certa medida, partem da ideia de uma dicotomia entre razão e emoção. Entretanto, acreditamos que esse pensamento problematiza pouco o pensamento racional de Habermas, ao desconsiderar que todo argumento racional tem fundo emocional. Na abertura do terceiro capítulo do livro, no momento em que discutem a racionalidade, Steiner et al. (2017) afirmam que "nos últimos tempos, no entanto, elementos não racionais, como histórias pessoais, foram adicionados ao modelo" (p.86, $\operatorname{tradução~nossa~}^{3}$ ). Contudo, em que medida esses outros elementos podem ser considerados não racionais? Muitos estudiosos argumentam que emoção e razão estão intimamente imbricadas, uma vez que a emoção é um componente do julgamento moral e da formação de preferências (Bickford, 2011; Krause, 2008; 2011; Morrell, 2017; Mouffe, 2005). Nesse sentido, acreditamos que razão e emoção não podem ser vistas como opostas, assim como as histórias de vida ou o humor não deveriam ser abordados como elementos não racionais.

É com as histórias de vida que Steiner et al. (2017) abre a parte dedicada às análises do DTM. O estudo empírico é sempre apresentado a partir de exemplos retirados dos grupos focais dos três países, o que favorece a compreensão do leitor. Em relação às histórias de vida, observou-se que elas podem ter um papel positivo ou negativo para a deliberação, uma vez que, em alguns momentos, contribuiu para elevar o nível da deliberação e, em outros, para diminuí-lo. Nesse ponto, o livro faz uma ressalva à ênfase da teoria deliberativa sobre o papel positivo das histórias, quando o estudo empírico com os grupos focais dos três países mostrou que nem todas as histórias contribuem para a qualidade deliberativa. $\mathrm{O}$ que contribuiu para que uma história seja positiva é o quão detalhada ela é e em que medida

\footnotetext{
${ }^{3}$ No original: "Rationality had the central place when the deliberative model was initially developed. In recent times, however, nonrational elements like personal stories were added to the model"
} 
ela se relaciona ao tema em discussão. "Um tipo prejudicial de história para a deliberação é aquela com poucos detalhes e sem qualquer ligação com a questão política em discussão" (Steiner et al., 2017, p.83, tradução nossa) ${ }^{4}$.

Da mesma forma que as histórias, mas com uma interferência menor, a presença do humor também pode contribuir para a mudança nos níveis de deliberação. Nos grupos focais, o humor contribuiu para elevar a qualidade da discussão, sendo importante para a boa convivência, por exemplo. Nesse ponto, os autores fazem uma ressalva em relação ao sarcasmo que tende a ser prejudicial, uma vez que reflete desrespeito. Outro aspecto analisado por Steiner e suas parceiras é a mudez, algo até então pouco explorado entre os deliberacionistas. A princípio, se pensarmos a deliberação enquanto um processo que requer comunicação, o silêncio pode parecer algo negativo. Contudo, a partir do estudo empírico, os autores encontraram "casos em que uma mudez diante de observações agressivas de outro participante ajudou a fazer com que a discussão voltasse a um alto nível de deliberação" (p.134, tradução nossa) .

Por fim, Steiner et al. (2017) indagam se nos longos momentos de alto nível de deliberação os atores justificam seus posicionamentos e conseguem chegar a acordos substantivos. A resposta é positiva nos três países, o que permite concluir que "uma longa deliberação pode compensar. Um círculo virtuoso se desenvolve, no sentido de que o raciocínio gera o raciocínio" (p.250, tradução nossa) .

Ainda que os autores façam uma distinção entre elementos racionais e não racionais, os casos empíricos evidenciam a importância de se analisar outros aspectos, além das trocas argumentativas, nos processos deliberativos. Levar em consideração a contribuição de histórias de vida, humor e mudez para a deliberação favorece também a inclusividade, um dos princípios norteadores da teoria.

\footnotetext{
${ }^{4}$ No original: "A harmful type for deliberation is a story with few details and lacking any linkage to the political issue under discussion".

${ }^{5}$ No original: "instances where a response of muteness to other actor's aggressive remarks has helped to transform a discussion back to a high level of deliberation".

${ }^{6}$ No original: "long deliberation can pay off. A virtuous circle develops, in the sense that reasongiving begets reason-giving".
} 


\section{Quem ajuda e quem atrapalha: líderes e spoilers deliberativos}

Nas experiências descritas por Steiner, Jaramillo, Maia e Mameli, a identificação dos Momentos Transformativos da Deliberação (DTM) permitiu que se percebesse a emergência de interlocutores que se mostraram importantes para implicar uma mudança positiva no fluxo de discussão nos grupos em que se inseriram. Nos três países, foi possível identificar agentes que, por meio de suas falas, conseguiram melhorar a qualidade deliberativa nas discussões em que se engajaram.

Nesses cenários, emerge a noção de uma liderança deliberativa, situação em que um ator "é frequentemente bem-sucedido em transformar a discussão em um alto nível de deliberação" e, ao mesmo tempo, "raramente é responsável por uma transformação a um nível baixo de deliberação" (p. 150, nossa tradução) ${ }^{7}$. Os casos empíricos ilustram que essas lideranças, embora mapeáveis, não são fixas: apesar de serem identificáveis os agentes que, de acordo com os DTMs, mais atuaram recuperando discussões com baixo nível de deliberação, não significa que esses agentes apenas ajudaram o processo deliberativo. À medida que os líderes se mostram, eles podem eventualmente não conseguir elevar uma discussão de baixo nível deliberativo; até mesmo, podem ser eles próprios os responsáveis pela queda qualitativa. Da mesma forma, outros sujeitos engajados na deliberação podem provocar uma melhora em sua qualidade. Em outros cenários, o caráter não-moderado das discussões pode dificultar mesmo a identificação de líderes espontâneos.

Os autores elencaram participantes da deliberação que, nas experiências dos três países, emergiram em papéis nítidos de liderança ao longo das discussões. Contextualizados os proferimentos, ilustraram-se diversas situações em que líderes conseguiram recuperar uma discussão que não ia bem. Na Colômbia, a atuação articulada de duas lideranças (uma exparamilitar e uma ex-guerrilheira) possibilitou certa harmonização em um cenário profundamente dividido, por meio de interpelações respeitosas e inclusivas. Na Bósnia e Herzegovina, um participante de origem sérvia se utilizou de recorrente justificação para

\footnotetext{
${ }^{7}$ No original: "frequently is successful at transforming the discussion to a high level of deliberation, and who is rarely responsible for a transformation to a low level of deliberation".
} 
inserir temas à pauta. No Brasil, as interpelações entre uma jovem moradora de favela e um policial ilustraram um senso de empatia e tomada da perspectiva do interlocutor, à medida que a adolescente passava a reconhecer e apontar os empecilhos potencialmente atravessados pelo policial em seu ambiente de trabalho. O esforço desses líderes viabilizou que, em várias situações, pudesse ser retomada a boa qualidade do processo deliberativo, ainda que a discussão estivesse pouco deliberativa por bastante tempo.

Cabe pontuar um estranhamento que uma conotação positiva de liderança em um processo deliberativo pode causar, tal qual apontado pelos próprios autores. Já que uma condição de igualdade entre os participantes é frisada enquanto ideal normativo para uma dinâmica de deliberação, uma noção de liderança poderia remeter à imposição hierárquica de uma indesejada relação de poder. No entanto, os autores ressaltam que estes sujeitos que atuaram como líderes nas experiências empíricas "tentaram influenciar a dinâmica da discussão para torná-la mais deliberativa" (p. 204, tradução nossa) ${ }^{8}$, em vez de procurarem reproduzir estruturas de poder. Ademais, os autores apontam a pertinência que, em uma perspectiva prática, a emergência de líderes deliberativos pode assumir na presença de spoilers deliberativos.

Os denominados spoilers deliberativos são atores que, de maneira oposta aos líderes, "frequentemente transformam a discussão de um alto para um baixo nível de deliberação" e "raramente transformam a discussão de um baixo para um nível alto de deliberação" (p.206, tradução nossa ${ }^{9}$ ). Em contrariedade aos princípios normativos da deliberação, os agentes que estão atuando como spoilers recorrentemente interrompem o fluxo da discussão por meio de asserções pouco respeitosas, histórias fora de contexto ou uso do sarcasmo. Nos exemplos elencados pelos autores, esses e diversos outros fatores são notáveis.

Na discussão entre ex-paramilitares e ex-guerrilheiros na Colômbia, a postura irônica e agressiva de uma das participantes implicou recorrentemente a queda do nível de qualidade deliberativa da discussão; no mesmo grupo, um outro integrante muitas vezes interrompeu

\footnotetext{
8 No original: "attempted to influence the discussion's dynamic to make it more deliberative".

9 No original: "frequently transform the discussion from a high to a low level of deliberation and who rarely transform a discussion from a low to a high level of deliberation".
} 
a manutenção de uma boa qualidade de discussão a partir de falas pouco coesas e ininteligíveis. Na Bósnia e Herzegovina, a fala pessimista de um participante procurou, por várias vezes, encerrar o assunto em pauta. No Brasil, a postura auto-centrada de uma policial fez com que a discussão se desviasse para histórias pessoais com pouca relação ao tópico discutido.

Cabe frisar que, assim como a posição de líder, os spoilers não são figuras fixas. Sendo assim, pode um mesmo agente proferir falas que auxiliem ou atrapalhem o fluxo da discussão. O mapeamento dos atores que mais melhoraram ou interromperam a qualidade das deliberações foi feito, tomando-se como base a perspectiva dos DTMs, de acordo com a reincidência dos momentos transformativos correspondentes. No entanto, percebe-se que, até nos exemplos mais polares dos dois cenários, mesmos agentes da deliberação atuam com certa mutabilidade ao longo dos processos de discussão.

\section{Considerações finais}

Ao nosso ver, o livro possui dois méritos principais. O primeiro é realizar uma análise empírica em situação de discussões com conflitos profundos, que leva em consideração outras formas de se comunicar para além das tradicionais trocas argumentativas, como histórias de vida e humor. O segundo ponto é em relação à metodologia, que, apesar de algumas limitações, dá a importância devida aos contextos das falas durante uma discussão. O relato das experiências nos três países ilustrou bem como outros fatores para além das trocas argumentativas podem auxiliar as discussões a manter um alto nível deliberativo. Nesse sentido, a descrição contextualizada de proferimentos de participantes permitiu observar como a emergência de líderes deliberativos não se deve apenas a um manejo articulado de trocas argumentativas; estes agentes são, também, bem sucedidos em compartilhar histórias pessoais pertinentes, ampliar noções de inclusão e empatia nos membros da deliberação, aliviar tensões latentes com bom-humor e cordialidade. As trocas argumentativas se manifestam nos relatos apresentados, mas os autores evidenciam como outros aspectos também emergem no processo deliberativo, frequentemente exercendo impactos muito positivos no estabelecimento de vínculos entre os sujeitos e na recuperação de discussões com baixa qualidade deliberativa. 
Em relação à metodologia, o DTM nos parece profícuo para identificar o que pode minar a deliberação e o que pode favorecê-la. Isso só é possível se o contexto da discussão é levado em consideração, uma vez que cada elemento analisado pelo livro, como retórica, humor e emoções, pode tanto prejudicar quanto favorecer a deliberação, a depender do momento e da forma com que aparecem na discussão. Steiner et al. não analisam os atos de fala de maneira isolada, mas sempre em contexto, o que é um mérito do livro e das reflexões que os resultados proporcionam.

O livro também abre caminhos para futuros estudos, como a aplicação do DTM em análises sistêmicas, ou seja, que consideram que a deliberação ocorre em diferentes ambientes, formais e informais, com características interacionais diversas (Chambers, 2012; Dryzek, 2016; Mansbridge et al., 2012). Além disso, em termos práticos, os autores apontam que as capacidades deliberativas podem ser ensinadas, inclusive, nas escolas. Estudantes e professores podem aprender a resolver conflitos, a partir de um diálogo respeitoso. Os autores observaram, por exemplo, que participantes dos grupos focais se tornaram mais deliberativos ao longo das discussões.

\section{Referências}

BÄCHTIGER, André; PARKINSON, John. Mapping and Measuring Deliberation: Towards a New Deliberative Quality. New York: Oxford University Press, 2019.

BICKFORD, Susan. Emotional talk and political judgment. The Journal of Politics, v. 73, n.4, 2011.

DRAKE, Anna; MCCULLOCH, Allison. Deliberative Consociationalism in Deeply Divided Societies. Comparative Political Theory, 10, 2011, pp. 372-92.

DRYZEK, John. Deliberative Democracy and Beyond: Liberals, Critics, Contestation. New York: Oxford, 2000.

DRYZEK, John. Deliberative Democracy in Divided Societies: Alternatives to Agonism and Analgesia. Political Theory, 33, 2005, pp. 218-42.

HABERMAS, Jürgen. Direito e Democracia entre facticidade e validade vol.2. Rio de Janeiro: Tempo Brasileiro , 2011.

KRAUSE, Sharon. Civil Passions: Moral Sentiment and Democratic Deliberation. New Jersey: Princeton University Press, 2008. 
MADDISON, Sarah, Relational Transformation and Agonistic Dialogue in Divided Societies, Political Studies, 63, 2015.

MANSBRIDGE, Jane; BOHMAN, James; CHAMBERS, Simone; CHRISTIANO, Thomas; FUNG, Archon; PARKINSON, John; THOMPSON, Dennis F; WARREN, Mark E. A systemic approach to deliberative democracy. In: John Parkinson; Jane Mansbridge (eds). Deliberative Systems.

Cambridge: Cambridge University Press, 2012.

MIGUEL, Luis Felipe. Os limites da deliberação. In: Democracia e representação: territórios em disputa. São Paulo: Editora Unesp, 2014

MORRELL, M. Empathy and democracy: Feeling, thinking and deliberation. State College: Penn State University Press, 2010.

MOUFFE, Chantal. Por um modelo agonístico de democracia. Revista de Sociologia e Política, Curitiba, 25, p. 11-23, 2005.

SANDERS, Lynn. Against Deliberation. Political Theory, v.5, n.2, 1997

STEINER, Jürg; JARAMILLO, Maria Clara; MAIA, Rousiley C.M; MAMELI, Simona. Deliberation across Deeply Divided Societies: Transformative Moments. New York: Cambridge University Press, 2017.

YOUNG, Iris Marion. Difference as a Resource for democratic communication. In: BOHMAN, James; REHG, William (org.). Essays on reason and politics: Deliberative Democracy. Cambridge: MIT Press, 1999.

\section{As autoras}

Gabriella Hauber é doutoranda do Programa de Pós-Graduação em Comunicação Social da UFMG e membro do Grupo de Pesquisa em Mídia e Esfera Pública (EME) da UFMG. gabihauber@gmail.com

Fernanda Nalon Sanglard é jornalista, mestre e doutora em comunicação; é pesquisadora de pós-doutorado do Grupo de Pesquisa em Mídia e Esfera Pública (EME) da UFMG.

nandanalon@yahoo.com.br

Pedro Henrique Bicalho Camelo é mestrando do Programa de Pós-Graduação em Comunicação Social da UFMG e membro do Grupo de Pesquisa em Mídia e Esfera Pública (EME) da UFMG. pedrobcamelo@gmail.com 